\title{
SPONASTRIME dysplasia
}

INSERM

\section{Source}

INSERM. (1999). Orphanet: an online rare disease and orphan drug data base.

SPONASTRIME dysplasia. ORPHA:93357

A rare, genetic, spondyloepimetaphyseal dysplasia disease characterized by short-limbed short stature (more pronounced in lower limbs) associated with characterisitic facial dysmorphism (i.e. relative macrocephaly, frontal bossing, midface hypoplasia, depressed nasal root, small upturned nose, prog nathism) and abnormal radiological findings, which include abnormal vertebral bodies (particularly in the lumbar region), striated metaphyses, generalized mild osteoporosis, and delayed ossification of the carpal bones. Progressive coxa vara, short dental roots, hypog ammag lobulinemia and cataracts may be occasionally associated. 